\title{
Influência da utilização de aditivos químicos no perfil da fermentação, no valor nutritivo e nas perdas de silagens de cana-de-açúcar
}

\section{Mateus Castilho Santos ${ }^{1}$, Luiz Gustavo Nussio², Gerson Barreto Mourão ${ }^{3}$, Patrick Schmidt ${ }^{4}$, Lucas José Mari ${ }^{5}$, José Leonardo Ribeiro ${ }^{5}$}

\footnotetext{
${ }^{1}$ Mestrando da USP/ESALQ.

2 Departamento de Zootecnia (USP/ESALQ)

${ }^{3}$ Departamento de Ciências Exatas (USP/ESALQ).

${ }^{4}$ Unesp/Campus Experimental de Registro.

${ }^{5}$ Doutorando da USP/ESALQ.
}

RESUMO - Avaliou-se o efeito do uso de aditivos químicos nas perdas de matéria seca, no perfil fermentativo e no valor nutritivo de silagens de cana-de-açúcar. O experimento foi realizado em delineamento inteiramente casualizado com quatro repetições por tratamento (sete tratamentos). Os seguintes aditivos foram utilizados na confecção das silagens: controle (sem aditivo), L. buchneri, óxido e carbonato de cálcio em doses de 1,0 e 1,5\% da massa verde e sulfato de cálcio a 1,0\% da massa verde, diluídos em 40 litros de água por tonelada de forragem. As variáveis analisadas foram: perdas totais e gasosas, produção de efluente, recuperação de matéria seca, composição química e valor nutritivo. As menores perdas fermentativas e gasosas foram observadas nas silagens com óxido ou carbonato de cálcio, que resultaram em maior taxa de recuperação de matéria seca. Da mesma forma, as silagens tratadas com estes aditivos apresentaram maior teor de carboidratos solúveis residuais e de ácido lático e reduzida fermentação alcoólica. As silagens tratadas com óxido e carbonato apresentaram, no momento da abertura, maior teor de cinzas, menor concentração de componentes fibrosos e maiores coeficientes digestibilidade da matéria seca e da matéria orgânica. O teor de proteína encontrado nessas silagens foi semelhante ao observado na forragem fresca. A ensilagem de cana-de-açúcar com L. buchneri e sulfato de cálcio possibilitou a obtenção de desempenho similar ao determinado com a silagem sem aditivos. Silagens tratadas com carbonato e óxido de cálcio apresentam maior desempenho durante o processo fermentativo.

Palavras-chave: ácido lático, carbonato de cálcio, carboidrato solúvel, etanol, óxido de cálcio

\section{Evaluation of chemical additives in the fermentation profile, nutritive value, and dry matters losses of sugar cane silages (Saccharum officinarum L.)}

\begin{abstract}
The objective of this trial was to evaluate the effects of chemical additives in the dry matter losses, fermentation profile, and nutritive value of sugar cane silages. The trial was carried out in a completely randomized experimental design with four replicates per treatment. The following additives were applied to the fresh forage during the ensiling: control (without additive), L. buchneri, calcium oxide and calcium carbonate, 1.0 and 1.5\% (wet basis) each, and calcium sulfate $1.0 \%$ (wet basis), all of them diluted in to $40 \mathrm{~L}$ of water per ton of fresh forage. The variables analyzed were: total and gaseous dry matter losses, dry matter recovery, fermentation end products, and nutritive value. The use of calcium oxide or calcium carbonate were effective in reducing dry matter losses and gaseous production and had the highest dry matter recovery rate. Both silages had also low ethanol content and, as a result, had greater concentrations of residual water soluble carbohydrates and lactic acid. The addition of calcium oxide and calcium carbonate at the time of ensiling produced silages with higher nutritive value compared with all other treatments, due to the increase of ash content and dry matter and organic digestibility and also, by reducing the fiber content. The crude protein content range was similar to the values observed in the fresh forage. The treatments with $L$. buchneri and calcium sulfate were ineffective in altering the fermentation process of sugar cane silages and became similar to the control silages. In summary, the overall analysis pointed out that the treatment containing calcium oxide and calcium carbonate improved the fermentation and storage process
\end{abstract}

Key Words: calcium carbonate, calcium oxide, ethanol, lactic acid, water-soluble carbohydrate

Este artigo foi recebido em 12/3/2007 e aprovado em 13/3/2008.

Correspondências devem ser enviadas para mateuscastilho@yahoo.com. 


\section{Introdução}

De modo geral, o uso da cana-de-açúcar tem sido preconizado para sistemas de produção animal. Características agronômicas como alto potencial de produção, variedades adaptadas aos diversos ambientes de produção e resistência a doenças e pragas têm feito desta planta um ingrediente interessante para os sistemas de produção animal. Aliado aos aspectos agronômicos tem-se, também, características desejáveis do ponto de vista zootécnico, como elevada produção de nutrientes digestíveis totais (NDT), baixo custo por tonelada de matéria seca, ponto de maturação coincidente com a escassez de forragem e grande amplitude de corte. Na última década, tem se observado aumento crescente do uso da silagem de cana-de-açúcar na alimentação animal. Ganhos em logística operacional e manejo do canavial e qualidade de vida no meio rural são os principais fatores que impulsionaram esta técnica.

No histórico sobre pesquisas com silagens de canade-açúcar, observa-se o interesse em identificar aditivos capazes de controlar a produção de etanol nesses volumosos. Alguns trabalhos realizados na década de 80 na América Central já alertavam para a elevada produção desse álcool. Preston et al. (1976) afirmavam que, quando ensilada sem aditivos, a cana-de-açúcar apresentava fermentação tipicamente alcoólica e perda de valor nutritivo. Kung Jr. \& Stanley (1982), trabalhando com silagens de cana sem aditivos e colhidas em diferentes estágios de maturação, observaram valores de etanol variando de 7,5\% até 17,5\% da MS. Alcántara et al. (1989), avaliando a dinâmica fermentativa em silagem de cana sem aditivos, observaram intensa redução no teor de carboidratos solúveis durante 30 dias de fermentação. De forma geral, os trabalhos realizados apresentavam valores adequados de $\mathrm{pH}$. Entretanto a elevada tolerância das leveduras ao baixo $\mathrm{pH}$ justifica os elevados teores de etanol encontrado nessas silagens. Segundo McDonald et al. (1991), esses microrganismos podem sobreviver em $\mathrm{pH}$ variando de 3,5 a 6,5 e algumas espécies podem sobreviver sob pH inferior a 2,0. De fato, a não utilização de aditivos implica em um processo de fermentação caracterizado pelo elevado desaparecimento de carboidratos solúveis e pela alta produção de etanol. Como conseqüências técnicas, verificam-se aumento das perdas de matéria seca, redução do valor nutritivo do alimento e redução de consumo voluntário pelos animais, como relatadas na literatura por diversos autores (Alli \& Backer, 1982; Kung Jr. \& Stanley, 1982; Pedroso, 2005; Schmidt, 2006; Queiroz, 2006).

Atualmente, alguns trabalhos têm sido realizados sobre a problemática da fermentação alcoólica e reforçam a idéia do uso de aditivos para a redução das perdas em silagens de cana-de-açúcar. Nesse contexto, a utilização de agentes alcalinizantes no processo de conservação tem mostrado efeitos positivos.

Os primeiros trabalhos conduzidos por Castrillón et al. (1878) e Alcântara (1989) iniciaram-se no final da década de 70 e 80 e envolviam a utilização de hidróxido de sódio na ensilagem da cana-de-açúcar. Segundo esses autores, a utilização de $\mathrm{NaOH}$ reduzia significativamente a produção de etanol e os teores de FDN e resultava em silagens com maior $\mathrm{pH}$ e maior teor de ácido lático, cinzas e carboidratos solúveis. Siqueira (2005) afirmou que a utilização de $\mathrm{NaOH}$ em silagem de cana-de-açúcar minimizou as perdas qualitativas desses alimentos. De acordo com Pedroso et al. (2007) silagens de cana tratadas com $\mathrm{NaOH}$ apresentam maiores coeficientes de digestibilidade e menores teores de FDN, FDA e lignina.

Ressalta-se que na década de 60 diversos estudos foram realizados nos Estados Unidos com carbonato de cálcio, aplicado exclusivamente ou em combinação com uréia, em silagens de milho (Klosterman et al., 1960; Simkins et al., 1965; Johnson et al., 1967; Essig, 1968; Owens et al., 1969). No Brasil existem poucos trabalhos avaliando o efeito dessa combinação de aditivos em silagens de sorgo (Vieira et al., 2004). Klosterman et al. (1960) concluíram que o carbonato de cálcio é um dos aditivos mais eficientes em aumentar o teor de ácidos orgânicos nos materiais ensilados. De acordo com Essig (1968), a adição de 0,5 a 1,0\% de carbonato de cálcio em silagens de milho melhora a fermentação e a aceitabilidade das silagens.

Atualmente, tem-se observado crescente utilização do óxido de cálcio em silagens de cana-de-açúcar em substituição ao hidróxido de sódio. Os autores sugerem silagens com reduzidas perdas de matéria seca e produção de gases e com maior valor nutritivo (Balieiro Neto et al., 2005a,b; Oliveira et al., 2004; Cavali et al., 2006). Nesta pesquisa, avaliou-se o efeito do uso de aditivos químicos nas perdas de matéria seca, no perfil fermentativo e no valor nutritivo de silagens de cana-de-açúcar.

\section{Material e Métodos}

O experimento foi realizado no Departamento de Zootecnia da Escola Superior de Agricultura Luiz de Queiroz (USP/ESALQ), em Piracicaba, São Paulo.

A variedade de cana-de-açúcar utilizada no experimento foi a RB72-454, colhida com aproximadamente 15 meses de idade. $\mathrm{O}$ material foi picado em equipamento estacionário regulado para corte com tamanho médio de partícula de $1 \mathrm{~cm}$. Depois de picada, a forragem foi imedia- 
tamente tratada com duas doses de $\mathrm{CaO}$ ou $\mathrm{CaCO}_{3}(1,0$ e 1,5\% na MV) e com uma única dose de gesso agrícola (1,0\% na MV), ambos os aditivos diluídos em solução aquosa com volume de 40 litros por tonelada de cana fresca. Os tratamentos controles consistiram de silagem de cana sem aditivo e tratada com Lactobacillus buchneri (2 g/t de MV de Lalsilcana ${ }^{\circledR}$ ), ambas com mesmo volume de água. A canade-açúcar contendo aditivo microbiano foi utilizada com o objetivo de se ter um controle positivo, com base no histórico de utilização desse produto, e para servir como referência para a avaliação de desempenho das demais silagens.

O delineamento estatístico utilizado foi o inteiramente casualizado com quatro repetições para cada tratamento. As variáveis obtidas no momento da abertura foram analisadas com base no procedimento GLM do programa estatístico SAS ${ }^{\circledR}$, versão 8 para Windows ${ }^{\circledR}$ (SAS, 1999). Para comparação de médias entre tratamentos, utilizou-se o teste de Tukey com nível de 5\% de significância.

Após o tratamento, a forragem foi imediatamente ensilada em baldes plásticos com capacidade de 20 litros. Cada balde possuía uma tampa adaptada com válvula tipo Bunsen e aproximadamente $2 \mathrm{~kg}$ de areia no fundo. A forragem foi compactada de modo que a densidade atingisse aproximadamente $500 \mathrm{~kg}$ de $\mathrm{MV} / \mathrm{m}^{3}$, como forma de garantir condições semelhantes de porosidade às silagens. Após o enchimento, os silos experimentais foram fechados com as tampas, vedados com auxilio de uma fita adesiva e mantidos em ambiente protegido.

Decorrido os 90 dias de armazenamento, os silos foram abertos e submetidos às avaliações previstas. Primeiramente, com o objetivo de quantificar perdas durante o período de estocagem, foi realizada pesagem individual dos baldes. Dessa forma, as perdas de matéria seca, produção de gases e efluente foram determinadas com base nas equações modificadas por Schmidt (2006). Com base nos valores de perda total, também foi possível determinar a recuperação final de matéria seca.

As amostras de cana-de-açúcar coletadas no momento da ensilagem, após a abertura dos silos e durante o ensaio de estabilidade, foram secas em estufas a $60^{\circ} \mathrm{C}$ por 72 horas, de acordo com Silva (1981), e posteriormente trituradas em moinho do tipo Wiley com peneira com perfurações de $1 \mathrm{~mm}$. A determinação da composição bromatológica foi realizada utilizando-se o método de espectroscopia de reflectância de infravermelho proximal (NIRS) (Berzaghi et al., 1997) em espectrômetro modelo NIRS 5000 (NIRSystems ${ }^{\circledR}$, Silver Spring, MD, USA). As amostras selecionadas pelo NIRS foram submetidas a análises convencionais no laboratório de bromatologia do Departamento de Zootecnia da USP/ESALQ.

Os teores de matéria seca e cinzas foram determinados segundo AOAC (1990). A fração proteína bruta foi obtida por condutividade térmica utilizando-se o equipamento Leco ${ }^{\circledR}$, modelo FP-528 (Leco Corporation, Michigan, USA). Os teores de FDN e FDA foram determinados pelo método seqüencial proposto pela ANKOM Fiber Analyser $\left(\right.$ ANKOM $^{\circledR}$ Technology Corporation, Fairport, NY). A análise da digestibilidade in vitro da matéria seca (DIVMS) foi obtida segundo o protocolo proposto pela ANKOM Daisy Incubator $\left(\right.$ Ankom ${ }^{\circledR}$ Technology Corporation, Fairport, NY) e descrito por Holden (1999).

No momento da ensilagem, após a abertura dos silos e durante o ensaio de estabilidade, também foram coletadas amostras úmidas para a confecção de extrato aquoso seguindo o protocolo proposto por Kung Jr. (1996). A determinação do $\mathrm{pH}$ foi realizada por meio de um potenciômetro digital (DIGMED ${ }^{\circledR}$ - DM20). O teor de etanol foi obtido diretamente por meio de leitura em autoanalisador YSI 2700 Select ${ }^{\circledR}$ (Biochemistry Analyser, Yellow Spring, OH, EUA) calibrado com soluções padronizadas de etanol (2 g/L). Para análise da concentração de carboidratos solúveis, utilizou-se o método colorimétrico adaptado de Dubois et al. (1956) com leitura em comprimento de onda de $490 \mathrm{~nm}$. A determinação da concentração de ácido lático foi realizada por meio da adaptação do método espectrofotométrico (565 nm) de Pryce (1969). O poder tampão foi determinado nas amostras de cana-de-açúcar no momento da ensilagem, segundo protocolo proposto Playne \& McDonald (1966). A partir do teor de matéria seca, do poder tampão e do teor de carboidratos solúveis das amostras de forragem fresca, foi calculada a capacidade de fermentação, segundo fórmula proposta por Weissbach \& Honig (1996), citados por Oude Elferink et al. (2000).

\section{Resultados e Discussão}

Os teores de matéria seca, FDN e FDA da forragem no momento da ensilagem (Tabela 1) estão de acordo com os valores relatados na literatura. Andrade et al. (2002), em experimento com diversas variedades de cana-de-açúcar, observaram teores de MS entre 24 e 37\%, de FDN entre 36 e $56 \%$ e de FDA entre 21 e $36 \%$. Do mesmo modo, os teores de PB mantiveram-se dentro da amplitude de 1,80 a 4,70\% da MS relatada por Faria (1993). Os parâmetros de digestibilidade estão dentro da faixa de variação de 54 a $64 \%$ preconizada por Boin \& Tedeschi (1993). Os altos teores de cinzas e de poder tampão observado nas forragens 
tratadas com agentes químicos comprovam o efeito do aditivo em modificar a ação tamponante e a fração mineral em forragens. Siqueira (2005) quantificou poder tampão de 24,4 e.mg de HCL/100g de MS para a cana fresca queimada e ensilada com $1,0 \%$ de $\mathrm{NaOH}$. Da mesma forma, a natureza alcalina do óxido e carbonato de cálcio resultou em forragens com valores de $\mathrm{pH}$ superiores. Os teores de carboidratos solúveis (Tabela 1) foram próximos ao relatado por Queiroz (2006), que obteve, no momento da ensilagem da cana-deaçúcar, valores de 23\% de CHO’S para a variedade RB 72-454 (a mesma utilizada neste experimento).

O coeficiente de fermentação calculado para as silagens foi superior ao indicado na literatura. De acordo com Weissbach \& Honig (1996), citados por Oude Elferink et al. (2000), forragens com teores insuficientes de carboidratos fermentescíveis ou com baixa porcentagem de matéria seca apresentam baixo coeficiente de fermentação $(<35)$. De fato, a capacidade fermentativa da cana-de-açúcar foi bem superior ao limite mínimo proposto por esses autores.

As perdas fermentativas em silagens de cana-de-açúcar podem ser elevadas, em decorrência da alta concentração de açúcares solúveis e de microrganismos indesejáveis. Neste estudo, aditivos químicos como o $\mathrm{CaCO}_{3}$ e CaO foram efetivos em reduzir as perdas totais e a produção de gases (Tabela 2) e resultaram em silagens com maiores recuperações de MS no momento da abertura dos silos. O tratamento da cana-de-açúcar com 1,5\% de $\mathrm{CaO}$ aparentemente foi o mais efetivo em reduzir as perdas totais. Silagens tratadas com L. buchneri e sulfato de cálcio apresentaram produção de gases, perdas totais e recuperação de matéria seca similares às da silagem controle. Os valores obtidos para essas silagens estão de acordo com os relatados por
Pedroso et al. (2005), que, conservando a cana-de-açúcar sem aditivo por 90 dias, quantificaram perdas totais de MS de $31,0 \%$.

Na literatura podem ser encontrados alguns trabalhos que comprovam o efeito de agentes alcalinizantes na redução das perdas em silagens de cana-de-açúcar. Balieiro Neto (2005a), avaliando o efeito de doses de $\mathrm{CaO}$ em silagens de cana-de-açúcar, observaram perdas totais e recuperação de matéria seca de 20 e $80 \%$, respectivamente, para as forragens tratadas com $2 \%$ de $\mathrm{CaO}$. Seguindo a mesma tendência, Oliveira et al. (2004) encontraram recuperações de MS de 77\% para as silagens de cana-de-açúcar acrescidas de $0,5 \%$ de cal hidratada, enquanto na silagem controle observaram recuperação de 72,1\% da MS.

Apesar dos benefícios obtidos em silagens de cana-deaçúcar, Owens et al. (1969) não encontraram o mesmo comportamento em silagens de milho. Avaliando o efeito da adição de $\mathrm{CaCO}_{3}$ na ensilagem de milho, esses autores observaram aumento das perdas totais de matéria seca ( $2,58 \%$ na silagem tratada contra $0,20 \%$ na silagem controle) e da produção de gases (6,65\% na silagem aditivada vs 4,70\% da MS na silagem sem aditivo). É possível que a extensão da fermentação seja a principal causa da elevação das perdas nessas silagens.

Entretanto, a análise conjunta dos dados de literatura e os resultados obtidos neste estudo comprovam que o tratamento de silagens de cana-de-açúcar com agentes alcalinizantes diminui as perdas totais e eleva a recuperação de MS. Além disso, a redução significativa da produção de gases (Tabela 2) com esses tratamentos explica as menores perdas totais. Provavelmente, as diferenças na população microbiana e no perfil fermentativo dessas silagens fazem

Tabela 1 - Composição química das silagens contendo cana-de-açúcar no momento da ensilagem

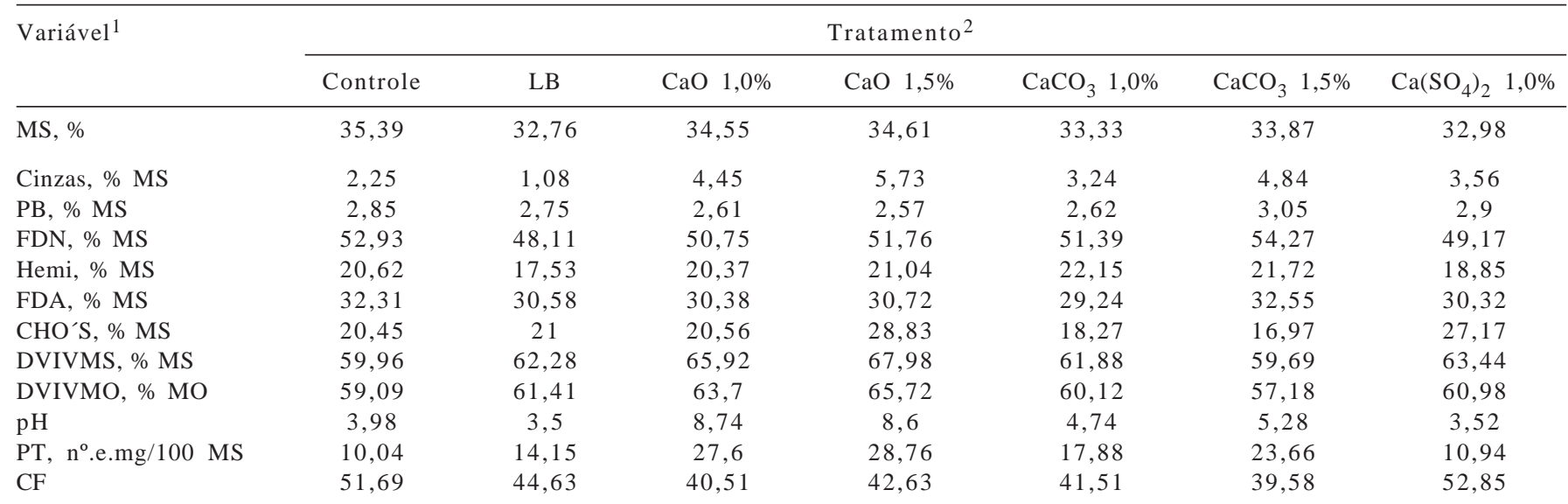

${ }^{1} \mathrm{MS}=$ matéria-seca; $\mathrm{PB}=$ proteína bruta; FDN = fibra em detergente neutro; Hemi = hemicelulose; FDA = fibra em detergente ácido; CHO'S = carboidratos solúveis; DIVMS = digestibilidade in vitro da matéria-seca; DIVMO = digestibilidade in vitro da matéria orgânica; PT = poder tampão; CF = coeficiente de fermentação.

${ }^{2}$ As doses dos aditivos químicos estão expressas com base na matéria verde; LB = Lactobacillus buchneri (2 g de produto comercial/t de MV). 
Tabela 2 - Perdas e produção de efluente das silagens de cana-de-açúcar tratadas com aditivos químicos e microbianos ${ }^{1}$

\begin{tabular}{lcccc}
\hline Tratamento $^{2}$ & Perdas totais (\% MS) & Perdas gasosas (\% MS) & Prod. efluente (kg/t MV) & Recuperação de MS (\%) \\
\hline Controle & $34,31 \mathrm{a}$ & $32,11 \mathrm{a}$ & $31,26 \mathrm{abcd}$ & $41,89 \mathrm{a}$ \\
$L$. buchneri & $35,78 \mathrm{a}$ & $32,83 \mathrm{a}$ & $20,55 \mathrm{~cd}$ & $65,69 \mathrm{c}$ \\
$\mathrm{CaO} 1,0 \%$ & $16,90 \mathrm{bc}$ & $15,12 \mathrm{~b}$ & $19,68 \mathrm{~d}$ & $83,22 \mathrm{c}$ \\
$\mathrm{CaO} 1,5 \%$ & $15,90 \mathrm{c}$ & $14,16 \mathrm{~b}$ & $32,82 \mathrm{ab}$ & $84,11 \mathrm{a}$ \\
$\mathrm{CaCO}_{3} 1,0 \%$ & $20,00 \mathrm{bc}$ & $17,19 \mathrm{~b}$ & $30,01 \mathrm{ab}$ \\
$\mathrm{CaCO}_{3} 1,5 \%$ & $21,00 \mathrm{~b}$ & $18,47 \mathrm{~b}$ & $30,07 \mathrm{bcd}$ & $79,00 \mathrm{~b}$ \\
$\mathrm{Ca}\left(\mathrm{SO}_{4}\right)_{2} 1,0 \%$ & $34,10 \mathrm{a}$ & $31,82 \mathrm{a}$ & $31,78 \mathrm{abc}$ & $65,90 \mathrm{c}$ \\
$\mathrm{CV}(\%)$ & 7,98 & 9,18 & 16,13 & 2,67
\end{tabular}

${ }^{1}$ Médias seguidas de letras diferentes nas colunas diferem $(P<0,05)$ entre si.

${ }^{2}$ As doses dos aditivos químicos estão expressas com base na matéria verde; $L$. buchneri $=2 \mathrm{~g}$ do produto comercial/t de MV.

Tabela 3 - Perfil fermentativo da silagem de cana-de-açúcar tratada com aditivos químicos e microbianos ${ }^{1}$

\begin{tabular}{|c|c|c|c|c|}
\hline Tratamento ${ }^{2}$ & $\mathrm{pH}$ & CHO’S solúveis & Etanol & Ácido lático \\
\hline Controle & $3,46 \mathrm{~d}$ & $2,98 b$ & $4,78 a$ & $2,00 \mathrm{abc}$ \\
\hline $\mathrm{CaO} 1,0 \%$ & $4,09 \mathrm{~b}$ & $6,50 \mathrm{ab}$ & $0,38 b$ & $3,66 a$ \\
\hline $\mathrm{CaO}$ 1,5\% & $4,46 a$ & $8,06 \mathrm{ab}$ & $0,37 b$ & $3,40 \mathrm{ab}$ \\
\hline $\mathrm{CaCO}_{3} \quad 1,0 \%$ & $3,70 \mathrm{c}$ & $9,28 a$ & $1,38 b$ & $3,50 \mathrm{ab}$ \\
\hline CV (\%) & 2,1 & 37,3 & 29,9 & 33,5 \\
\hline
\end{tabular}

${ }^{1}$ Médias seguidas de letras diferentes $(P<0,05)$ nas colunas diferem entre si.

${ }^{2}$ As doses dos aditivos químicos estão expressas com base na matéria verde; L. buchneri $=2 \mathrm{~g}$ do produto comercial/t de MV.

com que a extensão da fermentação promovida pelo uso do agente alcalinizante apresente resultados antagônicos, estimulando as perdas gasosas em silagens de milho e, no caso da ensilagem de cana-de-açúcar, diminuindo a fermentação alcoólica e reduzindo a produção de gases e as perdas totais. De fato, a alteração do $\mathrm{pH}$ e da fração mineral observadas nas forragens tratadas com óxido e carbonato de cálcio (Tabela 1) sugere redução da atividade de água desses materiais, proporcionando ambiente desfavorável para o desenvolvimento de leveduras.

A utilização de aditivos químicos e microbianos não reduziu significativamente a produção de efluente em comparação à silagem controle. Os valores obtidos com os tratamentos podem ser considerados baixos e estão de acordo com dados de literatura. Schmidt (2006), em pesquisa com cana-de-açúcar colhida aos 18 meses de idade e ensilada sem aditivo e com uréia, encontrou produção de efluente oscilando entre 35,6 e 42,5 kg/t de MV. A baixa capacidade desses aditivos em alterar o teor de matéria seca das forragens tratadas explica a ausência de efeito observada para essa variável.

A utilização de maior dose de $\mathrm{CaO}$ resultou em silagem com elevado pH no momento da abertura (Tabela 3). As silagens com diferentes doses de carbonato de cálcio apresentaram valores estatisticamente semelhantes, porém inferiores ao observado para as silagens tratadas com $1,0 \%$ de $\mathrm{CaO}$. As silagens controle e com L. buchneri ou gesso foram mais ácidas, com valores de $\mathrm{pH}$ significativamente semelhantes entre si. A reduzida ação tamponante e alcalinizante do gesso agrícola poderia explicar, em parte, o baixo $\mathrm{pH}$ dessa silagem.

Silagens com menor $\mathrm{pH}$ apresentaram menores concentrações de ácido lático (Tabela 3). O tratamento da cana-deaçúcar com cal virgem e calcário a 1,0\% resultou em silagens com altos valores de pH e maiores concentrações de ácido lático no momento da abertura. $\mathrm{O}$ inesperado sinergismo entre esses parâmetros, que contraria a tendência das fermentações clássicas, pode ser justificado pelo poder tampão (Tabela 1). A dissociação dos átomos presentes nos aditivos químicos gera cargas aniônicas capazes de neutralizar os íons hidrogênio oriundos dos ácidos orgânicos, principalmente o ácido lático. Dessa forma, silagens com altos teores de ácido lático apresentam maiores valores de $\mathrm{pH}$, em virtude da ação tamponante dos elementos formadores dos aditivos químicos. Além disso, o caráter básico do óxido e carbonato de cálcio eleva o $\mathrm{pH}$ da forragem fresca fazendo com que essas silagens apresentem maior $\mathrm{pH}$ mesmo em concentrações semelhantes de ácido lático. Por outro lado, o tamponamento dos ácidos produzidos pela fermentação serve de estímulo para a maior intensidade de 
conversão dos açúcares solúveis em ácido lático, aumentando a concentração desse produto final e evitando a produção de etanol (Tabela 3).

A significativa correlação positiva entre $\mathrm{pH}$ e concentração de ácido lático $(\mathrm{R}=0,52)$ observada nas silagens tratadas com agentes alcalinizantes (Tabela 3) tem sido relatada na literatura por diversos autores. Klosterman et al. (1960) concluíram que o carbonato de cálcio é um dos aditivos mais eficientes em aumentar o teor de ácidos orgânicos nos materiais ensilados. Owen et al. (1969), trabalhando com 1,0\% de carbonato de cálcio em silagem de milho, encontraram valores de $\mathrm{pH}$ de 4,3 para as silagens aditivadas e de 3,9 para as silagens controle. Esses autores encontraram concentração de ácido lático 7,91 \% da MS na silagem com carbonato de cálcio contra valores de aproximadamente 4,0\% da MS para a silagem controle.

Os altos valores de $\mathrm{pH}$ obtidos para as silagens tratadas com óxido de cálcio estão de acordo com os observados na literatura. Balieiro Neto et al. (2005a), trabalhando com diferentes doses de óxido de cálcio em silagem de cana-deaçúcar, observaram elevação significativa dos valores de pH final (4,44 para as silagens com 1,0\% de CaO e 3,66 para a silagem controle). Cavali et al. (2006), ao adicionarem 1,0 e 1,5\% de óxido de cálcio à silagem de cana-de-açúcar, observaram valores de 4,3 e 4,8, respectivamente. De acordo com Pedroso et al. (2007), silagens de cana-deaçúcar tratadas com agentes alcalinizantes geralmente apresentam pH superior ao nível máximo considerado adequado à estabilização de forragens ensiladas.

A inesperada correlação positiva na relação ácido lático e $\mathrm{pH}$ final das silagens tratadas com agentes alcalinizantes, aliada à relativa resistência das leveduras em se desenvolver em ambientes ácidos, faz do pH uma variável pouco efetiva em predizer a qualidade das silagens de cana-de-açúcar (Tabela 2). Neste estudo, as menores perdas de MS e produção de gases foram observadas nas silagens tratadas com óxido e carbonato de cálcio. O mesmo comportamento pode ser observado para os dados de recuperação de carboidratos solúveis e produção de etanol. De acordo com a Tabela 3, as silagens tratadas com óxido e carbonato de cálcio apresentaram alta recuperação de carboidratos solúveis residuais. Quando comparadas à silagem controle, essas silagens apresentaram diminuição significativa na produção de etanol. Certamente, o tratamento da cana-de-açúcar com agentes alcalinizantes sugere efeito inibidor do aditivo em relação ao crescimento de leveduras, pois as silagens tratadas com estes produtos apresentaram diminuição da fermentação alcoólica, elevada concentração de carboidratos solúveis e menor produção de gases e perdas totais, mesmo apresentando valores de $\mathrm{pH}$ relativamente altos.

A redução da produção de álcool e a maior recuperação de carboidratos solúveis por meio do uso de aditivos químicos já foi reportada na literatura por diversos pesquisadores. Alcântara et al. (1989), trabalhando com silagem de cana-de-açúcar tratada com 3,0\% de hidróxido de sódio na base seca, observaram concentrações significativamente menores de etanol $(0,22 \times 1,45 \%$ da MS para a silagem controle) e valor superior de carboidratos solúveis $(6,5 \% \times$ 4,4\%). Castrillón et al. (1978), em silagem de cana-de-açúcar tratada com $\mathrm{NaOH}$, encontraram reduções significativas na concentração de etanol. Pedroso et al. (2007), utilizando as dosagens de 1, 2, e 3,0\% de $\mathrm{NaOH}$ na massa verde da canade-açúcar, verificaram redução no teor de etanol, de 3,06\% na silagem controle para 2,4\% da MS, na média das silagens tratadas com esse produto.

O inadequado perfil fermentativo observado nas silagens controle e tratadas com L. buchneri e sulfato de cálcio pode ser justificado pela elevada tolerância das leveduras ao ambiente ácido. Segundo McDonald et al. (1991), esses microrganismos não são inibidos pelo baixo pH encontrado nas silagens. Diante desse fato, a significativa redução do $\mathrm{pH}$ nessas silagens (Tabela 3) aparentemente se mostrou ineficiente para o controle das leveduras. Além disso, o alto consumo de carboidratos solúveis e o significativo aumento da produção de etanol nessas silagens são constatações da intensa atividade desses microrganismos espoliadores, resultando nas maiores perdas totais e gasosas (Tabela 2). Pedroso et al. (2005), trabalhando com silagem de cana-de-açúcar sem aditivos, observaram desaparecimento de $74 \%$ de carboidratos solúveis durante 90 dias de fermentação. A média das silagens controle e com L. buchneri ou gesso agrícola apresentaram desaparecimento de carboidratos solúveis de aproximadamente $84 \%$ da MS durante os 90 dias de fermentação (Tabelas 1 e 3). Andrade \& Ferrari Jr. (2003) e Pedroso et al. (2005), ensilando cana-de-açúcar sem aditivos, encontraram concentrações de etanol de 5,75 e 6,81\% da MS, respectivamente, valores semelhantes aos obtidos nesse trabalho para as silagens controle ou com L. buchneri ou sulfato de cálcio.

Segundo McDonald et al. (1991), a produção de etanol representa perdas de $48,9 \%$ de MS dos substratos e essa perda é composta principalmente por carboidratos solúveis. Os dados observados neste trabalho ratificam essa informação: as silagens controle e com $L$. buchneri ou sulfato de cálcio apresentaram elevação significativa nos teores de etanol (Tabela 3) e, dessa forma, tiveram maiores perdas de MS (Tabela 2). De fato, a utilização de sulfato de cálcio e do 
aditivo microbiano L. buchneri apresentou neste estudo desempenho semelhante ao obtido na silagem controle para as variáveis analisadas. O baixo desempenho das silagens aditivadas com gesso atendeu à expectativa original, uma vez que essa silagem foi utilizada como controle negativo. A adição de $L$. buchneri foi explorada em outros trabalhos (Pedroso, 2007; Siqueira, 2005; Schmidt, 2006) como controle positivo e teve resultados favoráveis, o que, no entanto, não ocorreu neste estudo, uma vez que os resultados foram semelhantes aos das silagens não aditivadas. Não há evidência aparente que justifique esse comportamento, embora a silagem controle tenha apresentado perfil de fermentação superior ao esperado.

Conforme esperado, a utilização de aditivos químicos aumentou significativamente os teores de cinza das silagens em comparação à silagem controle e à tratada com aditivo microbiano (Tabela 4). Os maiores teores foram obtidos com as diferentes doses de óxido de cálcio e a maior dose de carbonato de cálcio.

$\mathrm{O}$ aumento fração mineral em silagens tratadas com aditivos químicos é relatado na literatura por diversos autores. Simkins et al. (1965), tratando a silagem de milho com $0,5 \%$ de carbonato de cálcio na MV, observaram teor de matéria mineral de 6,9\% na silagem tratada em comparação aos 5,2\% da MS para a silagem controle. Alcántara et al. (1989), utilizando 3,0\% de hidróxido de sódio na MS da silagem de cana-de-açúcar observaram elevações significativas nos teores de cinzas (7,03\% contra 4,60\% da MS para a silagem sem aditivo). Os teores de cinzas observados na Tabela 6 para as silagens tratada s com aditivos quimicos estão de acordo com os dados obtidos nos trabalhos realizados por Simkins et al. (1965) e Alcántara et al. (1989).

No momento da abertura, a concentração de proteína bruta foi significativamente maior para as silagens controle e com L. buchneri ou sulfato de cálcio e, de acordo com os valores encontrados na forragem fresca (Tabela 1), essas silagens apresentaram aumento dessa fração ao longo do período de conservação. Na análise dos dados das perdas e do padrão fermentativo, essas silagens apresentaram desempenho insatisfatório. Possivelmente, o desaparecimento de outras frações orgânicas solúveis e o ambiente favorável para a atividade de microrganismos espoliadores favoreceu o aumento da concentração da fração protéica dessas forragens. Na silagem controle, a utilização de óxido e carbonato de cálcio resultou em silagens com menores porcentagens de proteína bruta. Entretanto, comparando os teores da forragem fresca (Tabela 1) aos da silagem no momento da abertura (Tabela 4), observa-se pequena variação dessa fração nessas silagens. Aparentemente, o processo fermentativo da cana-de-açúcar apresenta pouco efeito na degradação da proteína, uma vez que houve pequena alteração dessa fração ao longo do tempo e os valores obtidos para as silagens no momento da abertura (Tabela 4) estão dentro da amplitude preconizada por Faria (1993) para a forragem fresca ( 1,80 a $4,70 \%$ da MS).

No momento da abertura, os maiores valores de FDN e FDA (Tabela 4) foram observados nas silagens controle e L. buchneri, seguidas pela silagem tratada com sulfato de cálcio. Não foi verificada diferença entre as silagens quanto à fração hemicelulose. Queiroz (2006), trabalhando com aditivos microbianos em silagens de cana-de-açúcar, observou elevado teor de fibra nas silagens controle e tratada com dose comercial de $L$. buchneri. A silagem controle apresentou teores de FDN e FDA de 77,7\% e 45,61\%, respectivamente. O tratamento com $L$. buchneri resultou em valores semelhantes, com 75,56\% de FDN e 45,55\% de FDA. Para a silagem de cana-de-açúcar colhida crua e sem aditivos, Siqueira (2005) constatou teores de FDN e FDA de 75,1 e $48,7 \%$, respectivamente. Ao ensilar essa mesma forragem com L. buchneri, esse autor obteve valores de 66,7 e $45,6 \%$ para as variáveis FDN e FDA, respectivamente.

A utilização de óxido e carbonato de cálcio foi efetiva em reduzir a concentração de componentes da parede celular nas silagens aditivadas em relação à silagem controle

Tabela 4 - Valor nutritivo das silagens de cana-de-açúcar no momento da abertura dos silos experimentais ${ }^{1}$

\begin{tabular}{|c|c|c|c|c|c|c|c|}
\hline \multirow[t]{2}{*}{ Tratamento 2} & Cinzas & PB & FDN & FDA & HEMI & DIVMS & \multirow{2}{*}{$\begin{array}{l}\text { DVIVMO } \\
\% \text { da MO }\end{array}$} \\
\hline & \multicolumn{6}{|c|}{$\%$ da MS } & \\
\hline Controle & $1,75 d$ & $3,98 a$ & $67,10 \mathrm{a}$ & $43,78 a$ & $23,32 a$ & $48,74 d$ & $47,96 \mathrm{~d}$ \\
\hline L. buchneri & $2,13 \mathrm{~d}$ & $3,88 a$ & $65,12 \mathrm{a}$ & $42,25 a$ & $22,88 a$ & $49,06 \mathrm{~d}$ & $48,30 d$ \\
\hline $\mathrm{CaO}$ 1,0\% & $6,09 \mathrm{ab}$ & $2,67 c d$ & 52,56de & $35,40 \mathrm{c}$ & $17,16 \mathrm{c}$ & $70,45 b$ & $67,47 b$ \\
\hline $\mathrm{CaO}$ 1,5\% & 7,29a & $2,51 \mathrm{~d}$ & $54,83 \mathrm{~cd}$ & $35,07 c$ & $19,76 b$ & $74,21 \mathrm{a}$ & $72,34 a$ \\
\hline $\mathrm{CaCO}_{3} 1,0 \%$ & $4,71 \mathrm{c}$ & $3,08 b$ & $55,84 c$ & $35,41 c$ & $20,43 b$ & $58,60 \mathrm{c}$ & $54,83 c$ \\
\hline $\mathrm{CaCO}_{3} 1,5 \%$ & $6,04 \mathrm{ab}$ & $2,87 \mathrm{bc}$ & $51,58 \mathrm{e}$ & $34,94 c$ & $16,64 \mathrm{c}$ & $61,76 \mathrm{c}$ & $57,34 \mathrm{c}$ \\
\hline $\mathrm{Ca}\left(\mathrm{SO}_{4}\right)_{2} \quad 1,0 \%$ & $5,29 b c$ & $3,85 a$ & $61,83 b$ & $39,10 \mathrm{~b}$ & $22,73 a$ & $52,06 \mathrm{~d}$ & $50,33 d$ \\
\hline CV $(\%)$ & 12,4 & 3,7 & 2,4 & 3,4 & 4,9 & 2,4 & 2,5 \\
\hline
\end{tabular}

${ }^{1}$ Médias seguidas de letras diferentes nas colunas diferem entre si $(P<0,05)$.

${ }^{2}$ As doses dos aditivos químicos estão expressas com base na matéria verde; L. buchneri $=2 \mathrm{~g}$ do produto comercial/t de MV. 
(Tabela 4). No momento da abertura dos silos, diminuições significativas foram observadas para as variáveis FDN e hemicelulose nas silagens tratadas com $1,0 \%$ de $\mathrm{CaO}$ e com $1,5 \%$ de $\mathrm{CaCO}_{3}$. Cavali et al. (2006) observaram efeito dos diferentes doses de óxido de cálcio nas frações da parede celular da cana-de-açúcar. Segundo esses autores, doses de 1,73 e 1,49\% de CaO resultaram em silagens com teores mínimos de FDN e FDA (38,6 e 22,5\%, respectivamente). Os baixos teores de FDN e FDA apresentados na Tabela 4 para os tratamentos contendo óxido e carbornato de cálcio estão de acordo com os resultados obtidos por Balieiro Neto et. (2005), que, ao adicionarem 2,0\% de cal virgem a silagem de cana-de-açúcar, observaram baixos teores dessas fraçoes (49,47\% para o FDN e 36,52\% para o FDA).

De modo geral, o mesmo comportamento foi observado para a digestibilidade da matéria seca e matéria orgânica em todas as silagens (Tabela 4). A utilização de L. buchneri e sulfato de cálcio na cana-de-açúcar resultou em silagens com coeficientes de digestibilidade menores e semelhantes aos da silagem controle. Os coeficientes de digestibildade obtidos com as silagens controle e L. buchneri (Tabela 4) foram muito próximos aos observados por Siqueira (2005), ao ensilar a cana-de-açúcar crua e tratada com L. buchneri, cujo coeficiente de digestibilidade da MS foi de aproximadamente $50 \%$.

A utilização de $\mathrm{CaO}$ e $\mathrm{CaCO}_{3}$ elevou significativamente a digestibilidade da silagem de cana-de-açúcar. Os maiores coeficientes foram observados para as silagens com 1,5\% de óxido de cálcio, seguida daquela com 1,0\% do mesmo aditivo. Balieiro Neto et al. (2005b) observaram que a ensilagem da variedade de cana-de-açúcar 86-2480 com 2,0\% de óxido de cálcio, resultou em silagens com 79,23\% de DIVMS. Cavali et al. (2006), trabalhando com diferentes níveis de $\mathrm{CaO}$, estimaram valores máximos de DIVMS de 81,2\% para a silagem de cana-de-açúcar aditivada com 1,8\% de óxido de cálcio. Pedroso et al. (2007) relataram valores máximos de 67,3\% de DIVMS para a silagem de cana tratada com 3,0\% de $\mathrm{NaOH}$.

Os dados também comprovam aumento na digestibilidade da silagem de cana-de-açúcar tratada com carbonato de cálcio em relação à silagem controle (Tabela 4). Os reduzidos teores de FDN, FDA e hemicelulose observados nas silagens contendo carbonato de cálcio (Tabela 4) possivelmente justificam os altos coeficientes de digestibilidade.

Em comparação à silagem controle, a utilização de óxido e carbonato de cálcio no momento da ensilagem reduziu as perdas totais e gasosas e inibiu a fermentação alcoólica. Dessa forma, o favorecimento do perfil fermentativo, a redução das perdas durante o armazenamento e a solubilização parcial da hemicelulose contribuíram para a menor partici- pação da fração fibrosa na matéria seca e resultou em silagens com maiores coeficientes de digestibilidade. Dessa forma, a utilização de agentes alcalinizantes no momento da ensilagem consiste em estratégia potencial para aumento do valor alimentar das silagens. Apesar disso, a literatura disponível apresenta poucas informações sobre o desempenho de animais alimentados com silagens de cana aditivadas com agentes alcalinos.

\section{Conclusões}

De modo geral, a adição de óxido e carbonato de cálcio favorece o processo de ensilagem da cana-de-açúcar. Durante o período de conservação, a utilização desses aditivos promove redução das perdas totais e gasosas, inibição da fermentação alcoólica e maior recuperação de carboidratos, resultando em silagem com valor nutritivo semelhante ao da forragem fresca. Os aditivos L. buchneri e sulfato de cálcio são pouco efetivos em alterar a fermentação alcoólica e reduzir as perdas em silagem de cana-deaçúcar, pois resultam em volumosos com valor nutritivo semelhante ao da silagem não aditivada.

\section{Literatura Citada}

ALCÁNTARA, E.; AGUILERA, A.; ELLIOT, R. et al. Fermentation and utilization by lambs of sugarcane harvested fresh and ensiled with and without NaOH. 4. Ruminal kinetics. Animal Feed Science and Technology, v.23, p.323-331, 1989.

ALLI, I.; BAKER, B.E. Studies on the fermentation of chopped sugarcane. Animal Feed Science and Technology, v.7, p.411-417, 1982 .

ANDRADE, J.B.; FERRARI JR., E.; POSSENTI, R.A. et al. Produção e composição de cultivares de cana-de-açúcar. In: REUNIÃO ANUAL DA SOCIEDADE BRASILEIRA DE ZOOTECNIA, 39., 2002, Recife. Anais... Recife: Sociedade Brasileira de Zootecnia, 2002. (CD-ROM).

ANDRADE, J.B.; FERRARI JR., E. Composição química da silagem de cana-de-açúcar tratada com uréia e diferentes doses de hidróxido de sódio. In: REUNIÃO ANUAL DA SOCIEDADE BRASILEIRA DE ZOOTECNIA, 40., Santa Maria, 2003. Anais... Santa Maria: Sociedade Brasileira de Zootecnia, 2003. (CD-ROM).

ASSOCIATION OF OFFICIAL ANALYTICAL CHEMISTS - AOAC. Official methods of analysis. 15.ed. Arlington: 1990. v.1, $1117 \mathrm{p}$.

BALIEIRO NETO, G.; SIQUEIRA, G.R.; NOGUEIRA, J.R et al. Perdas na ensilagem da cana-de-açúcar cv. IAC86/2480 (Saccharum officinarum L.) com doses de óxido de cálcio. In: REUNIÃO ANUAL DA SOCIEDADE BRASILEIRA DE ZOOTECNIA, 42., 2005, Goiânia. Anais... Goiânia: Sociedade Brasileira de Zootecnia, 2005a. (CD-ROM).

BALIEIRO NETO, G.; SIQUEIRA, G.R.; NOGUEIRA, J.R. et al. Valor nutritivo da silagem de cana-de-açúcar cv. IAC 86/2480 (Saccharum officinarum L.) com doses de óxido de cálcio antes e depois da ensilagem e com 3, 6 e 9 dias após abertura do silo. In: REUNION DE LA ASOCIACÓN LATINOAMERICANA DE PRODUCCIÓN ANIMAL, 19., 2005, Tampico. Anais... Tampico: ALPA, 2005b. (CD-ROM). 
BERZAGHI, P.; COZZI, G.; ANDRIGHETTO, I. The use of near infrared analysis for in situ studies. Journal of Dairy Science, v.80, n.12, p.3263-3270, 1997.

BOIN, C.; TEDESCHI, L.O. Cana-de-açúcar na alimentação de gado de corte. In: SIMPÓSIO SOBRE NUTRIÇÃO DE BOVINOS, 5., 1993, Piracicaba. Anais... Piracicaba: Fundação de Estudos Agrários Luiz de Queiroz, 1993. p.107-126.

CASTRILLÓN, M.V.; SHIMADA, A.S.; CALDERÓN, F.M. Manipulacion de la fermentacion en ensilajes de caña de azucar y su valor alimenticio para borregos. Técnica Pecuária en México, v.35, p.48-55, 1978.

CAVALI, J.; PEREIRA, O.G.; SOUSA, L.O. et al. Silagem de cana-deaçúcar tratada com óxido de cálcio: composição bromatológica e perdas. In: REUNIÃO ANULA DA SOCIEDADE BRASILEIRA DE ZOOTECNIA, 43., 2006, João Pessoa. Anais... João Pessoa: Sociedade Brasileira de Zootecnia, 2006. (CD-ROM).

DUBOIS, M.; GILLES, K.A.; HAMILTON, J.K. et al. Colorimetric method for determination of sugars and related substances. Analytical Chemistry, v.28, p.350, 1956.

ESSIG, H.W. Urea-limestone-treated silage for beef cattle. Journal of Animal Science, v.27, n.3, p.730-738, 1968.

FARIA, V.P. O uso da cana-de-açúcar para bovinos no Brasil. In: SIMPÓSIO SOBRE NUTRIÇÃO DE BOVINOS, 5., 1993, Piracicaba. Anais... Piracicaba: Fundação de Estudos Agrários Luiz de Queiroz, 1993. p.1-16.

HOLDEN, L.A. Comparison of methods of in vitro dry matter digestibility for ten feeds. Journal of Dairy Science, v.82, n.8, p.1791-1794, 1999.

JOHNSON, R.R.; McCLURE, K.E.; KLOSTERMAN, E.W. et al. Corn plant maturity. III. Distribution of nitrogen in corn silage treated with limestone, urea and diammonium phosphate. Journal of Animal Science, v.26, n.1, p.394-399, 1967.

KLOSTERMAN, E.W.; JOHNSON, R.R.; SCOTT, H.W. et al. Whole plant and ground ear corn silages, their acid content, feeding value and digestibility. Journal of Animal Science, v.19, n.2, p.522-532, 1960.

KUNG JR., L.; STANLEY, R.W. Effect of stage of maturity on the nutritive value of whole-plant sugarcane preserved as silage. Journal of Animal Science, v.54, p.689-696, 1982.

KUNG JR., L. Preparation of silage water extracts for chemical analyses. Standard operating procedure - 0012.03 .96 ed. University of Delaware - Ruminat Nutrition Lab. - Worrilow 309. 1996.

McDOnAlD, P.; Henderson, A.R.; Heron, S.J.E. The biochemistry of silage. 2.ed. Marlow: Chalcomb Publications, 1991. 340p.

OLIVEIRA, M.W.; MENDES, L.C.; MARQUES, W.P. et al. Adição de hidróxido de cálcio à silagem de cana. In: CONGRESSO NACIONAL DE ZOOTECNIA, 9., 2004, Brasília. Anais... Brasília: ZOOTEC, 2004. (CD-ROM).
OUDE ELFERINK, S.J.W.H.; DRIEHUIS, F.; GOTTSCHAL, J.C. et al. Silage fermentation processes and their manipulation. In: FAO ELETRONIC CONFERENCE ON TROPICAL SILAGE, 1999, Rome. Silage making in the tropics with emphasis on smallholders. Procedings... Rome: FAO, 2000. p.17-30.

OWENS, F.N.; MEISKE, J.C.; GOODRICH, R.D. Effects of calcium sources and urea on corn silage fermentation. Journal of Dairy Science, v.52, n.11, p.1817-1822, 1969.

PEDROSO, A.F.; NUSSIO, L.G.; PAZIANI, S.F. et al. Dinâmica da fermentação e da microflora epífita em silagem de cana-deaçúcar. Scientia Agrícola, v.62, n.5, p.427-432, 2005.

PEDROSO, A.F.; NUSSIO, L.G.; LOURES, D.R.S. et al. Efeito do tratamento com aditivos químicos e inoculantes bacterianos nas perdas e na qualidade de silagens de cana-de-açúcar. Revista Brasileira de Zootecnia, v.36, n.3, p.558-564, 2007.

PLAYNE, M.J.; McDONALD, P. The buffering constituints of herbage and of silage. Journal of the Science of Food and Agricultural, v.17, p.264-268, 1966.

PRESTON, T.R.; HINOJOSA, C.; MARTINEZ, L. Ensiling of sugar cane with ammonia molasses and mineral acids. Tropical Animal Production, v.1, p.120-126, 1976.

PRYCE, J.D. A modification of Barker-Summerson method for the determination of lactic acid. Analyst, v.94, p.1151-1152, 1969.

QUEIROZ, O.C.M. Associação de aditivos microbianos na ensilagem e o desempenho de vacas em lactação recebendo silagem de cana-de-açúcar comparada a volumosos tradicionais. Piracicaba: Escola Superior de Agricultura "Luiz de Queiroz”, 2006. 99p. Dissertação (Mestrado em Agronomia) Escola Superior de Agricultura "Luiz de Queiroz", 2006.

STATISTICAL ANALYSIS SYSTEM - SAS. SAS user's guide: statistics. Cary: 1999. 965p.

SCHMIDT, P. Perdas fermentativas na ensilagem, parâmetros digestivos e desempenho de bovinos de corte alimentados com rações contendo silagens de cana-de-açúcar. Piracicaba: Escola Superior de Agricultura "Luiz de Queiroz", 2006. 228p. Dissertação (Mestrado em Agronomia) - Escola Superior de Agricultura "Luiz de Queiroz”, 2006.

SILVA, D.J. Análise de alimentos (métodos químicos e biológicos) Viçosa, MG: Editora UFV, 1981. 166p.

SIMKINS, K.L.; BAUMGARDT, B.R.; NIEDERMEIER, R.P. Feeding value of calcium carbonated-treated corn silage for dairy cows. Journal of Dairy Science, v.48, p.1315-1318, 1965.

SIQUEIRA, G.R. Cana-de-açúcar (Saccharum officinarum L.) ensilada com aditivos químicos e microbianos. Jaboticabal: Universidade Estadual Paulista “Júlio de Mesquita Filho”, 2005. 92p. Dissertação (Mestrado em Zootecnia) - Universidade Estadual Paulista “Júlio de Mesquita Filho”, 2005.

VIEIRA, F.A.P.; BORGES, I.; STEHLING, C.A.V. et al. Qualidade de silagens de sorgo com aditivos. Arquivo Brasileiro de Medicina Veterinária e Zootecnia, v.56, n.6, p.764-772, 2004. 